\title{
Geoprocessamento aplicado à observação da sazonalidade das larvas da mosca Dermatobia hominis no município de Seropédica - RJ
}

\author{
[Geoprocessing applied to the seasonality of Dermatobia hominis larvae in the municipality \\ of Seropédica, Rio de Janeiro] \\ F.S. Souza ${ }^{1,5}$, A.H. Fonseca ${ }^{2}$, M.J.S. Pereira ${ }^{2}$, J.X. Silva ${ }^{3,4}$, M.H.B. Goes ${ }^{4}$ \\ ${ }^{1}$ Aluno de pós-graduação - UFRRJ - Seropédica, RJ \\ ${ }^{2}$ Departamento de Parasitologia Animal - UFRRJ - Seropédica, RJ \\ ${ }^{3}$ Departamento de Geografia - UFRJ - Rio de Janeiro, RJ \\ ${ }^{4}$ Departamento de Geociências - UFRRJ - Seropédica, RJ \\ ${ }^{5}$ Bolsista do CNPq.
}

\begin{abstract}
RESUMO
Associações espaço-temporais entre os fatores envolvidos na distribuição sazonal das larvas da mosca do berne - Dermatobia hominis (Linnaeus Jr., 1781) (Diptera: Cuterebridae) - em bovinos foram analisadas por geoprocessamento, utilizando-se o sistema de análise geoambiental da Universidade Federal do Rio de Janeiro, no município de Seropédica, RJ. Na primavera, $50 \%$ da área do município foi muito favorável ao desenvolvimento dessa mí́ase. Esse grau de favorabilidade reduziu-se para $35 \%, 23 \%$ e $12 \%$ no verão, outono e inverno, respectivamente.
\end{abstract}

Palavras-chave: bovino, berne, Diptera, sistemas de informação, epidemiologia

\begin{abstract}
Space-temporal associations between factors involved in the seasonal distribution of Dermatobia hominis (Linnaeus Jr., 1781) (Diptera: Cuterebridae) fly larvae in cattle were analyzed by geoprocessing using the geo-environment system of the Universidade Federal do Rio de Janeiro, in the municipality of Seropédica, RJ. In the spring, $50 \%$ of the area was favorable, reducing its extension to $35 \%$ in the summer, to $23 \%$ in the fall and to $12 \%$ in the winter.
\end{abstract}

Keywords: cattle, Diptera, larvae, information systems, epidemiology

\section{INTRODUÇ̃̃O}

Dermatobia hominis (Linnaeus Jr., 1781) (Diptera: Cuterebridae), díptero conhecido vulgarmente no Brasil como mosca do berne, está presente em várias regiões do país. Infesta um número relativamente grande de hospedeiros, sendo os bovinos os mais acometidos. A larva dessa mosca, uma vez presente na pele desses animais, causa a chamada miíase furuncular ou dermatobiose, determinando perdas econômicas à indústria coureiro-calçadista pela depreciação do couro (Oliveira, 1983).
As condições ambientais são fatores importantes para o desenvolvimento da $D$. hominis, logo, o estudo da variação sazonal do berne permite conhecer a época de maior intensidade parasitária, assim como correlacionar os fatores atuantes no crescimento populacional das larvas (Bellato et al., 1986).

$\mathrm{Na}$ região Sudeste do Brasil, os meses de primavera e verão - período chuvoso - são os mais favoráveis à ocorrência de larvas de Dermatobia sobre os bovinos (Magalhães e Lima, 1988; Maio et al., 1999). As menores

Recebido em 1 de agosto de 2005

Aceito em 7 de janeiro de 2007

Endereço para correspondência (corresponding address)

Rua Nove, 95 - 26015-260 - Nova Iguaçu, RJ

E-mail: souzamedvet@ig.com.br 
infestações ocorrem nos meses de outono e inverno, período de menor precipitação pluvial.

Creighton e Neel (1952) e Neel et al. (1955) relacionaram as variações altimétricas entre 400 e 1.500 metros como as mais favoráveis à dermatobiose. No Brasil, a ocorrência da Dermatobia já foi registrada em altitudes inferiores a 400 metros (Maia e Guimarães, 1985; Ribeiro et al., 1989).

Os sistemas geográficos de informação (SGI) podem ser utilizados para mostrar e analisar a territorialidade dos fenômenos neles representados. A aplicabilidade dos SGI na epidemiologia tem sido bem sucedida em estudos na área de saúde pública, como os realizados por Cruz Marques (1987) e Brooker (2002). Em medicina veterinária, Cringoli et al. (2001) e Diersmann et al. (2001 e 2002) aplicaram o geoprocessamento no estudo de áreas de risco e prevalência de filariose em cães na Itália e na análise epidemiológica do carrapato Boophilus microplus no Brasil, respectivamente.

O sistema de análise geoambiental/UFRJ $\left(\mathrm{SAGA} / \mathrm{UFRJ}^{\circledR}\right.$ ) permite, por meio da função avaliação ambiental, a superposição de mapas temáticos digitais, gerando resultados que, analisados pela função assinatura, produzem relatórios em percentual, pixels e hectares (Xavier-da-Silva, 2001).

O objetivo deste trabalho foi delimitar, no município de Seropédica-RJ, áreas favoráveis à ocorrência da dermatobiose, quantificar, em percentagem, as áreas de maior favorabilidade e discriminar os fatores ambientais presentes nessas áreas por estação do ano.

\section{MATERIAL E MÉTODOS}

O município de Seropédica, com área de 48.600 hectares, foi escolhido devido à disponibilidade da base de dados georreferenciados por Goes (1994). Usou-se o sistema de informação SAGA/UFRJ ${ }^{\circledR}$ do qual foram utilizadas as funções avaliação ambiental e assinatura.
Inicialmente foi realizado um inventário das condições ambientais vigentes no município para selecionar os fatores relevantes à ocorrência das larvas da mosca $D$. hominis.

$\mathrm{Na}$ hierarquização dos fatores, construção da árvore de decisão, atribuição de pesos aos fatores (Fig. 1) e notas às categorias (Tab. 1 e 2), aplicou-se o procedimento de avaliação por multicritérios, sugerido por Xavier-da-Silva (2001). Cada mapa temático foi constituído por categorias que receberam notas de zero a 10. A nota zero representou a menor participação da categoria no evento. $\mathrm{O}$ intervalo de notas de 1 a 4 foi atribuído às categorias julgadas não favoráveis à ocorrência da Dermatobia; as notas 5 e 6 , às categorias pouco favoráveis; 7 e 8 às favoráveis e 9 e 10 àquelas muito favoráveis. Notas de 11 a 23 foram usadas para representar nos mapas temáticos as categorias que não fizeram parte da análise.

As avaliações foram realizadas conforme indicado na árvore de decisão. O fator natural foi elaborado a partir da avaliação dos mapas temáticos de solo e de geomorfologia, o fator geoambiental da análise dos mapas dos fatores naturais e cobertura vegetal e o fator topográfico da avaliação dos mapas temáticos de declividade e de altitude (Fig. 1). Os mapas de favorabilidade à dermatobiose por estação do ano resultaram de avaliações usando os fatores geoambientais, topográficos e climáticos produzidos. Os pesos atribuídos aos fatores geoambiental e topográfico e as notas de categorias que os compõem foram mantidos fixos para as quatro estações do ano, enquanto as notas das categorias que compõem os fatores climáticos variaram (Tab. 3).

Os quatro mapas, um para cada estação do ano, resultantes das avaliações foram submetidos a assinaturas, para quantificar o percentual dos diferentes graus de favorabilidade para a área total do município. Em seqüência, também foram realizadas assinaturas nas áreas de maior favorabilidade para discriminar as categorias dos fatores ambientais selecionados presentes em cada área por estação do ano. 


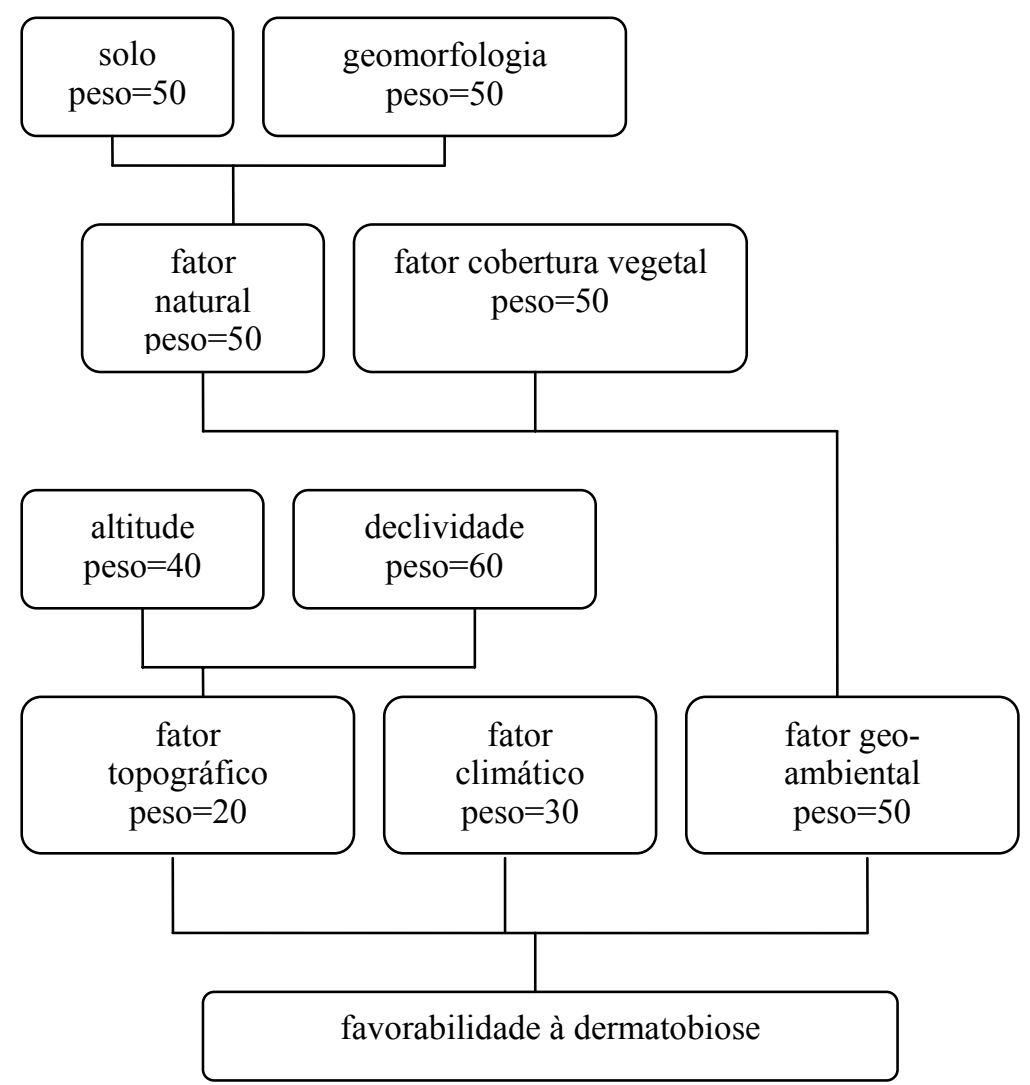

Figura 1. Árvore de decisão com os pesos atribuídos aos fatores, em percentagem, segundo sua importância na ocorrência da dermatobiose.

Tabela 1. Mapas dos grupos de fatores geoambientais e topográficos segundo categorias e notas atribuídas

\begin{tabular}{|c|c|c|c|c|c|}
\hline \multicolumn{2}{|c|}{ Mapa de solo } & \multicolumn{2}{|c|}{ Mapa de geomorfologia } & \multicolumn{2}{|c|}{ Mapa de altitude } \\
\hline Categoria & Nota & Categoria & Nota & Categoria & Nota \\
\hline Podzólico 1 & 10 & $\begin{array}{l}\text { Borda dissecada de } \\
\text { planalto estrutural } \\
\text { Patamar dissecado em } \\
\text { colinas e vales }\end{array}$ & 6 & $0-40 \mathrm{~m}$ & 10 \\
\hline Podzólico 2 & 10 & estruturais. & 8 & $0-20 \mathrm{~m}$ & 10 \\
\hline Cambissolo 1 & 7 & $\begin{array}{l}\text { Encostas de Talus } \\
\text { Colinas estruturais de }\end{array}$ & 10 & $20-40 m$ & 10 \\
\hline Cambissolo 2 & 7 & $\begin{array}{l}\text { piemonte } \\
\text { Colinas } \\
\text { aplainadas/depressões }\end{array}$ & 10 & $40-80 \mathrm{~m}$ & 10 \\
\hline Planossolo & 5 & $\begin{array}{l}\text { assoreadas } \\
\text { Colinas isoladas/ilhas }\end{array}$ & 5 & $80-120 \mathrm{~m}$ & 10 \\
\hline Gley húmico & 0 & estruturais & 8 & $120-160 \mathrm{~m}$ & 10 \\
\hline Gley pouco húmico & 2 & $\begin{array}{l}\text { Rampas de colúvio } \\
\text { Planície colúvio- }\end{array}$ & 7 & $160-200 \mathrm{~m}$ & 10 \\
\hline Gley indiscriminado & 3 & $\begin{array}{l}\text { aluvionar } \\
\text { Planície aluvionar de }\end{array}$ & 4 & $200-320 \mathrm{~m}$ & 10 \\
\hline Solo Aluvial & 4 & cobertura & 4 & $320-400 \mathrm{~m}$ & 10 \\
\hline
\end{tabular}


Tabela 2. Mapas dos grupos de fatores geoambientais e topográficos segundo categorias e notas atribuídas

\begin{tabular}{|c|c|c|c|c|c|}
\hline \multicolumn{2}{|c|}{$\begin{array}{l}\text { Mapa de } \\
\text { declividade }\end{array}$} & \multicolumn{2}{|c|}{$\begin{array}{c}\text { Mapa de } \\
\text { cobertura vegetal }\end{array}$} & \multicolumn{2}{|c|}{$\begin{array}{l}\text { Categorias que não fizeram parte } \\
\text { da análise }\end{array}$} \\
\hline Categoria & Nota & Categoria & Nota & Categoria & Nota \\
\hline \multicolumn{6}{|l|}{ Classe entre } \\
\hline $0-2,5 \%$ & 4 & Mata de altitude & 10 & Área fora de análise & 11 \\
\hline Classe entre $2,5 \%-5 \%$ & 5 & Macega e sítios rurais & 8 & Rede de drenagem & 12 \\
\hline Classe entre $5 \%-10 \%$ & 10 & Veg. herb. higrófita & 2 & Auto-estrada & 13 \\
\hline Classe entre $10-20 \%$ & 10 & Reflorestamento & 8 & $\begin{array}{l}\text { Estrada pavimentada } \\
\text { Estrada não } \\
\text { pavimentada tráfego }\end{array}$ & 14 \\
\hline Classe entre $20-40 \%$ & 8 & Pastagem & 10 & $\begin{array}{l}\text { permanente } \\
\text { Estrada não } \\
\text { pavimentada tráfego }\end{array}$ & 15 \\
\hline \multirow[t]{8}{*}{ Classe $>40 \%$} & 7 & $\begin{array}{l}\text { Cultivo } \\
\text { Sítio urbano ou }\end{array}$ & 8 & periódico & 16 \\
\hline & & industrial & 0 & Caminho & 17 \\
\hline & & Extrativismo mineral & 0 & Ferrovia & 18 \\
\hline & & Afloramento de rocha & 0 & Áreas urbanas & 19 \\
\hline & & Área institucional & 0 & Dique & 20 \\
\hline & & & & Toponímia & 21 \\
\hline & & & & Rio Guandu & 22 \\
\hline & & & & Limite municipal & 23 \\
\hline
\end{tabular}

Tabela 3. Categorias dos mapas e notas atribuídas aos fatores geoambientais, topográficos e climáticos para a avaliação que gerou os graus de favorabilidade à ocorrência de dermatobiose em bovinos, no município de Seropédica, RJ

\begin{tabular}{cccccc}
\hline $\begin{array}{c}\text { Fator } \\
\text { geoambiental }\end{array}$ & \multicolumn{2}{c}{$\begin{array}{c}\text { Fator } \\
\text { topográfico }\end{array}$} & \multicolumn{2}{c}{ Fator climático } \\
\hline Categoria & Nota & Categoria & Nota & Categoria & Nota \\
\hline Nota 2 & 4 & Nota 6 & 6 & Primavera & 10 \\
Nota 3 & 4 & Nota 7 & 8 & Verão & 9 \\
Nota 4 & 4 & Nota 8 & 8 & Outono & 8 \\
Nota 5 & 6 & Nota 9 & 10 & Inverno & 6 \\
Nota 6 & 6 & & & & \\
Nota 7 & 8 & & & & \\
Nota 8 & 8 & & & & \\
Nota 9 & 10 & & & & \\
\hline
\end{tabular}

\section{RESULTADOS E DISCUSSÃO}

Os resultados das associações entre os fatores envolvidos na distribuição sazonal das larvas da mosca $D$. hominis são mostrados em um mapa digital (Fig. 2, 3, 4 e 5), segundo a estação do ano e o grau de favorabilidade à ocorrência do evento. $\mathrm{Na}$ Tab. 4 encontram-se os resultados que quantificaram as áreas de ocorrência da dermatobiose. As assinaturas realizadas nos gradientes mais favoráveis por estação do ano permitiram a quantificação e a discriminação das categorias dos mapas temáticos componentes. Em altitudes abaixo de $80 \mathrm{~m}$ na primavera, verão, outono e inverno, estão concentradas $82 \%, 76 \%$, $95 \%$ e $90 \%$ das áreas muito favoráveis, respectivamente. Em declividades inferiores a 10\%, estão $70 \%, 60 \%, 77 \%$ e $55 \%$ dessas áreas. O solo podzólico predomina nas áreas mais favoráveis, nas quatro estações do ano. Esse solo caracteriza-se por ser de fácil drenagem, não hidromórfico, dando condições à fácil penetração de larvas de Dermatobia e seu conseqüente desenvolvimento. As feições geomorfológicas onde se concentram as áreas muito favoráveis coincidentes nas quatro estações são as colinas aplainadas com depressões assoreadas com 25\%, 26\%, 34\% e $28 \%$ na primavera, verão, outono e inverno, respectivamente. Deve-se ressaltar a presença de $31 \%$ de áreas muito favoráveis na primavera e de $23 \%$ no outono, ocupadas por planícies colúvioaluvionares e, ainda, áreas de $22 \%, 31 \%$ e $45 \%$, com colinas estruturais de piemonte no verão, outono e inverno, na seqüência. 
Geoprocessamento aplicado à observação...

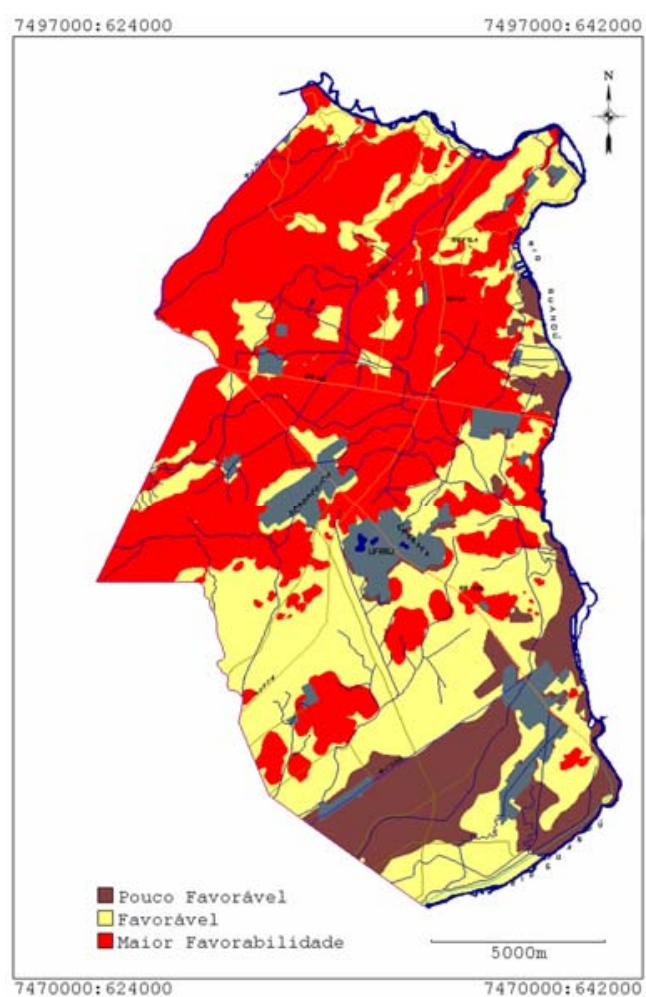

Figura 2. Dermatobiose em bovinos na primavera. Município de Seropédica. Resolução de 25 metros.

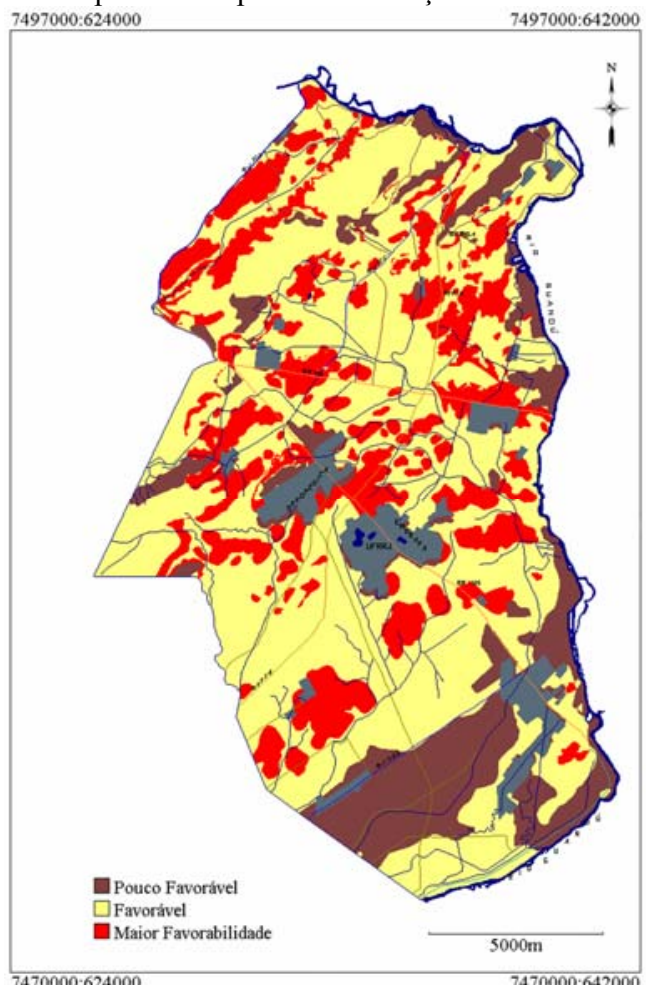

Figura 4. Dermatobiose em bovinos no outono. Município de Seropédica. Resolução de 25 metros.

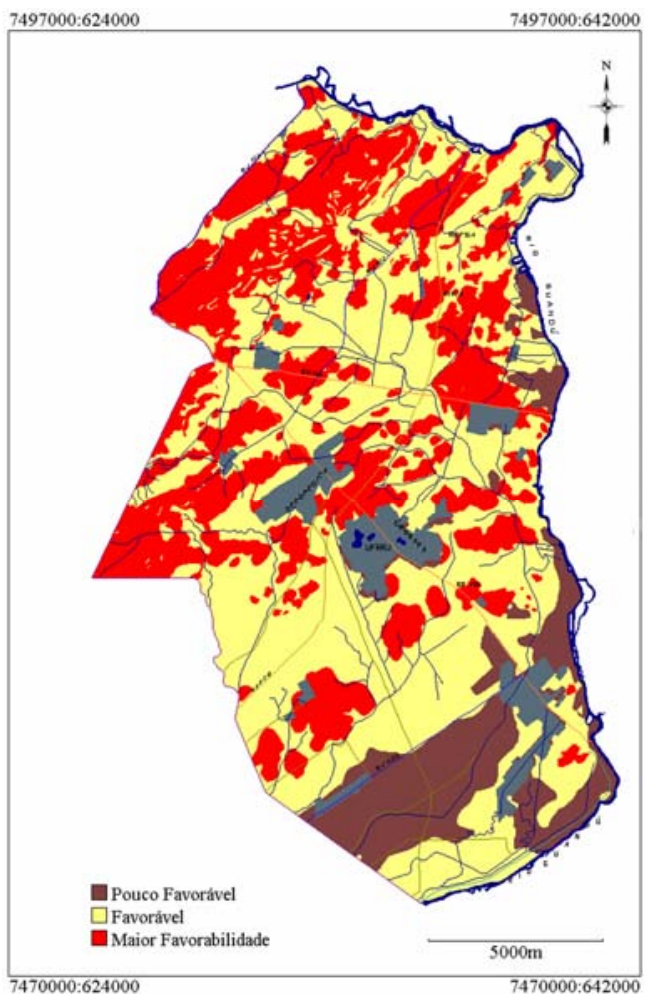

Figura 3. Dermatobiose em bovinos no verão. Município de Seropédica. Resolução de 25 metros.

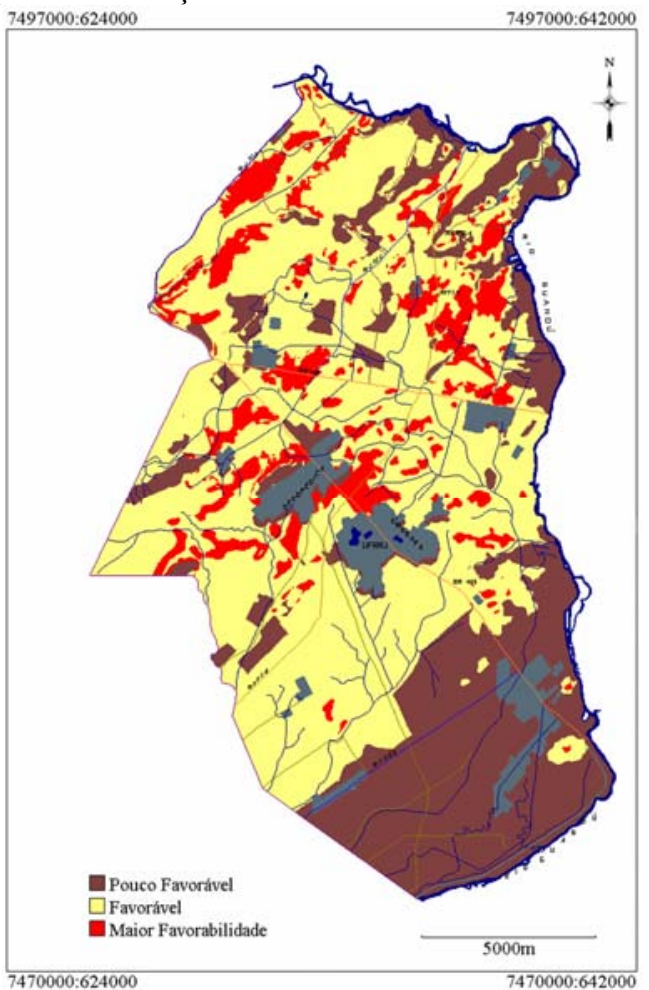

Figura 5. Dermatobiose em bovinos no inverno. Município de Seropédica. Resolução de 25 metros. 
Tabela 4. Áreas de ocorrência de dermatobiose em bovinos, por grau de favorabilidade (\%), segundo a estação do ano, em Seropédica - RJ

\begin{tabular}{|c|c|c|c|}
\hline Estação & $\begin{array}{c}\text { Muito } \\
\text { favorável }\end{array}$ & Favorável & $\begin{array}{c}\text { Pouco } \\
\text { favorável }\end{array}$ \\
\hline Primavera & 50 & 38 & 12 \\
\hline Verão & 35 & 52 & 13 \\
\hline Outono & 23 & 60 & 17 \\
\hline Inverno & 12 & 58 & 30 \\
\hline
\end{tabular}

A predominância de áreas de ocorrência do grau muito favorável foi assinalada na primavera, com $50 \%$, e verão, com $35 \%$, períodos em que são registradas as maiores médias de temperatura, precipitação pluvial e umidade relativa. Maio et al. (1999) consideraram esses fatores como decisivos para a infestação de bernes em bovinos nessa região. Estes resultados assemelham-se aos observados para a região Sudeste do Brasil, onde os meses de primavera e verão, período chuvoso, são os mais favoráveis à ocorrência de larvas de Dermatobia em bovinos (Magalhães e Lima, 1988; Maio et al., 1999). Como observado neste trabalho, as menores infestações foram assinaladas nos meses de outono (23\%) e inverno $(12 \%)$.

Pode-se destacar a versatilidade desse díptero em ajustar-se a diferentes características climáticas, adaptando-se às condições mais favoráveis dentro de cada clima, como mencionado por Creighton e Neel (1952).

Portanto, a análise exploratória dos componentes das áreas muito favoráveis sugere haver interação entre estes, colaborando para formar um sistema propício a altas infestações durante as diferentes épocas, favorecendo o ciclo da Dermatobia.

A metodologia empregada neste estudo mostrouse eficiente para a análise epidemiológica da dermatobiose, pois constitui importante elemento de apoio à tomada de decisões e é mais uma ferramenta para a elaboração de programas de controle integrado dessa ectoparasitose.

\section{REFERÊNCIAS BIBLIOGRÁFICAS}

BEllato, V.; PAlOSCHI, C.G.; SOUZA, A.P. et al. Variação sazonal das larvas da mosca do berne em bovinos no Planalto Catarinense. EMPASC - Comunicado Técnico, $101,1986.7 \mathrm{p}$.
BROOKER, S. Schistosomes, snails and satellites. Acta Trop., v.82, p.141-149, 2002.

CREIGHTON, J.T.; NEEL, W.W. Biologia y combate del torsalo o nuche, Dermatobia hominis (L. Jr.): Reseña bibliográfica. Turrialba, v.2, p.59-65, 1952.

CRINGOLI, G.; RINALDI, L.; VENEZIANO, V. et al. A prevalence survey and risk analysis of filariosis in dogs from the Mt. Vesuvius area of southern Italy. Vet. Parasitol., v.102, p.243-252, 2001

CRUZ MARQUES, A. Human migration and the spread of malaria in Brazil. Parasitol. Today, v.3, p.166-170, 1987.

DIERSMANN, E.M.; FONSECA, A.H.; PEREIRA, M.J. Uso de sistema de informação geográfica na análise epidemiológica de Boophilus microplus - uma alternativa viável. In: JORNADA DE INICIAÇÃO CIENTÍFICA DA UFRRJ, 11., 2001. Anais... Rio de Janeiro: UFRRJ, 2001. v.11. p.259-260 (Resumo expandido).

DIERSMANN, E.M.; FONSECA, A.H.; PEREIRA, M.J. Análise espacial e temporal do Boophilus microplus (CANESTRINI, 1887) (ACARI: IXODIDAE) através de um SGI. In: CONGRESSO BRASILEIRO DE PARASITOLOGIA VETERINÁRIA, 12., 2002, Rio de Janeiro. Anais... Rio de Janeiro, 2002. 1 CD-ROM.

GOES, M.H.B. Diagnóstico ambiental por geoprocessamento do Municipio de Itaguai (RJ). 1994. 744f. Tese (Doutorado) Universidade Estadual Paulista, Rio Claro, SP

MAGALHÃES, F.E.P.; LIMA, J.D. Freqüência de larvas de Dermatobia hominis (L. Jr.) em bovinos de Pedro Leopoldo, Minas Gerais. Arq. Bras. Med. Vet. Zootec., v.40, p.361-367, 1988

MAIA, A.A.M.; GUIMARÃES, M.P. Distribuição sazonal de larvas de Dermatobia hominis (Linnaeus Jr. 1781) (Díptera: Cuterebridae) em bovinos de corte na região de Governador Valadares, Minas Gerais. Arq. Bras. Med. Vet. Zootec., v.37, p.469-475, 1985.

MAIO, F.G.; SOUZA, W.M.; GRISI, L. et al. Distribuição sazonal das larvas de Dermatobia hominis (Linnaeus Junior, 1781) em bovinos leiteiros no município de Seropédica, Rio de Janeiro, Brasil. Rev. Univ. Rural, Série Ciênc. Vida, v.21, p.25-36, 1999.

NEEL, W.W.; URBINA, O.; VIALE, E. et al. Ciclo biológico del torsalo (Dermatobia hominis L. Jr.) en Turrialba, Costa Rica Turrialba, v.5, p.91-104, 1955.

OLIVEIRA, G.P. Fatores que afetam economicamente a produção de couro de bovinos. Arq. Biol. Tecnol., v.26, p.353-358, 1983.

RIBEIRO, P.B.; COSTA, P.R.P.; BRUM, J.G.W. et al. Flutuação populacional de Dermatobia hominis (L. Jr., 1781) sobre bovinos no município de Pelotas, R.S. Arq. Bras. Med. Vet. Zootec., v.41, p.223-231, 1989.

XAVIER-DA-SILVA, J. (Ed). Geoprocessamento para análise ambiental. Rio de Janeiro. Bertraud Brasil, 2001. $228 \mathrm{p}$. 